\title{
Pengaruh Penerapan Model Pembelajaran Kooperatif Tipe Think-Paire Share Dan Tipe Two - Stay Two - Stray Terhadap Peningkatan Kemampuan Berfikir Kritis Siswa dalam Pembelajaran Ekonomi Bisnis (Quasi Eksperimen Pada Siswa Kelas X Di Smk N 2 Karawang)
}

\author{
Ining Mukarromah ${ }^{1 *}$, Nanang Fatah², Tjutju Yuniarsih ${ }^{3}$ \\ 1,2,3 Universitas Pendidikan Indonesia \\ *E-mail: iningmukarromah@ student.upi.edu
}

\begin{abstract}
Abstrak : Penelitian ini merupakan kuasi eksperimen berbentuk kelompok eksperimen dan kontrol pretes-postes, dengan perlakuan pendekatan pembelajaran kooperatif Think-Paire Share dan pembelajaran Two - Stay Two - Stray 1. Hasil perhitungan menunjukan bahwa nilai Sig. sebesar 0,000 $(0,000<0,05)$ berarti terdapat perbedaan peningkatan kemamuan berfikir kritis peserta didik antara kelas eksperimen dan kelas control. Pada Levene's Test terlihat bahwa $\mathrm{F}=1,576(\mathrm{p}=0,127)$ karena $\mathrm{p}$ diatas 0,05 , menunjukkan bahwa tidak ada perbedaan varian pada nilai post testberarti data bersifat equal atau homogen. Terlihat pada $t$-test for Equality of Mean bahwa nilai t Hitung sebesar 10, 590 signifikasni $>0.05$ artinya t hitung lebih besar dari t tabel 1,9944 (dengan $\mathrm{df}=70$ ). Selain dari t Hitung perbedaan kemampuan berfikir kritis peserta pada kelas yang menggunakan metode Think-Pair Share dengan kelas yang menggunakan metode Two Stay - Two Stray dapat dilihat pada niai signifkansi yang diperoleh yaitu 0,000 yang mana hasil ini lebih keci dari signifikansi alpha yaitu 0,025. Dari hasil ini dapat dikatakan bahwa ada perbedaan kemampuan berfikir kritis peserta didik pada kelas yang menggunakan metode Think-Pair Share dengan kelas yang menggunakan metode Two Stay - Two Stray.

Keyword: Kemampuan berfikir kritis, Think-Pair Share, Two Stay - Two Stray
\end{abstract}

UTILITY: Jurnal Ilmiah Pendidikan dan Ekonomi

Permalink: https://journal.stkipnurulhuda.ac.id/index.php/utility/article/view/320

How to cite (APA): Mukarromah, I., Fatah, N., \& Yuniarsih, T. (2018). Pengaruh Penerapan Model Pembelajaran Kooperatif Tipe Think-Paire Share Dan Tipe Two - Stay Two - Stray Terhadap Peningkatan Kemampuan Berfikir Kritis Siswa dalam Pembelajaran Ekonomi Bisnis. UTILITY: Jurnal Ilmiah Pendidikan Dan Ekonomi, 2(2), 85-97.

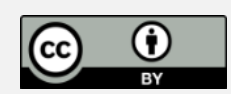

This is an open access article distributed under the terms of the Creative Common Attribution 4.0 International License, which permits unrestricted use, distribution, and reproduction in any medium, provided the original work is properly cited. 


\section{PENDAHULUAN}

Beberapa teori tentang berfikir kritis dari Fischer dan Farrar (1988), bahwa kemampuan berfikir kritis siswa dipengaruhi kemampuan kognitiv dan ketrampilan dalam penerapan (Anderson, Howe, R., Halliday, \& Low, 2001) , Robert Duron (2006) menjelaskan kemampuan berfikir kritis dipengaruhi perkembangan kognitif, lingkungan belajar yang efektif, dan penilaian berbasis hasil, menyediakan guru dengan kerangka yang berguna (Duron, Limbach, \& Waugh, 2006), Menurut Vygotsky (1978), siswa mampu tampil di tingkat intelektual yang lebih tinggi ketika diminta untuk bekerja dalam situasi kolaboratif daripada ketika diminta untuk bekerja secara individual. keragaman kelompok dalam hal pengetahuan dan pengalaman memberikan kontribusi positif terhadap proses pembelajaran (R. Ennis, 1991). Bruner (1985) menyatakan bahwa metode pembelajaran kooperatif meningkatkan strategi pemecahan masalah karena siswa dihadapkan dengan interpretasi yang berbeda dari situasi tertentu. Sistem dukungan sebaya memungkinkan pelajar untuk internalisasi baik pengetahuan eksternal dan keterampilan berpikir kritis dan mengubahnya menjadi alat untuk fungsi intelektual (Gokhale, 1995).

Banyak penelitian yang telah dilakukan mengenai penerapan suatu metode pembelajaran hanya saja penelitian-penelitian tersebut lebih banyak meneliti pengaruh pembelajaran dengan metode Think-Pair Share dan Two stay- Two stray lebih banyak pada mata pelajaran fisika, kimia dan bahasa yang digunakan tidak untuk peningkatan berfikir kritis hanya tebatas pada motivasi dan prestasi belajar siswa dan hanya menerapkan satu metode pembelajaran saja sedangkan yang meneliti efektifitas penerapan model pembelajaran Think-Pair Share dan Two stay- Two stray secara bersamaan dalam rangka peningkatan berfikir kritis siswa pada mata pelajaran ekonomi belum ada.

\section{METODE}

Metode Penelitian ini merupakan jenis penelitian eksperimen yaitu metode quasi experimen atau eksperimen semu. Penelitian ini bertujuan untuk mengetahui efektifitas penerapan teknik pembelajaran Think Pair Share dan Two Stay Two Stray terhadap kemampuan berfikir kritis siswa.

a. Teknik Pengumpulan data 
Teknik pengumpulan data dalam penelitian ini dilakukan dengan teknik tes. Tehnik tes uraian sangat tepat untuk digunakan dalam rangka menguji kemampuan berpikir kritis siswa (R. H. Ennis, 1993), karena kemampuan berpikir kritis termasuk dalam kemampuan berpikir tingkat tinggi, sehingga tepat bila diukur dengan menggunakan tes uraian.

\section{Uji Validitas}

Menghitung harga korelasi setiap butir soal dengan menggunakan rumus korelasi Pearson Product Moment, yaitu persamaan (1) :

$$
r_{x y}=\frac{n \cdot\left(\sum X Y\right)-\left(\sum X\right)\left(\sum Y\right)}{\sqrt{\left\{n \cdot\left(\sum X^{2}\right)-\left(\sum X\right)^{2}\right\}}\left\{n \cdot\left(\sum Y^{2}\right)-\left(\sum Y\right)^{2}\right\}}
$$

Keterangan:

r_xy : Koefisien korelasi

$\mathrm{n} \quad$ : Jumlah sampel

Y : Jumlah skor total seluruh system

$\mathrm{X}$ : Jumlah skor tiap item

Melakukan perhitungan uji t dengan rumus:

Thitung $=\frac{\sqrt[r]{n-2}}{\sqrt{1-r^{2}}}$

Keterangan :

$\mathrm{r}$ : Koefisien korelasi hasil rhitung

$\mathrm{n}$ : Jumlah responden

Mencari ttabel $=\mathrm{t} \propto(\mathrm{dk}=\mathrm{n}-2)$, dengan $\alpha=0,05$

Membuat kesimpulan, dengan kriteria pengujian sebagai berikut :

- Jika thitung > ttabel, berarti valid, atau

- Jika thitung < ttabel, berarti tidak valid.

Untuk menghitung validitas item butir soal penelitian ini, menggunakan bantuan SPSS versi 24 dan membandingkan Item-Total Correlation dengan rtablel $=0,388$.

\section{Uji Reliabilitas}


Dalam penelitian ini, validitas dihitung dengan menggunakan rumus alpha cronbach, (Sugiono, 2006:24) persamaan (2) sebagai berikut:

$$
\mathrm{r} 11=\mathrm{r}_{11}=\frac{K}{k-1}\left(1-\frac{\sum \sigma_{i}^{2}}{\sigma^{2}}\right)
$$

Keterangan :

r11 = Koefisien reliabilitas yang dicari

$\mathrm{k}=$ Jumlah butir soal

$\sigma_{1}^{2} \quad=$ Varians butir soal

$\sigma^{2}=$ Varians skor test

b. Teknik Analisa Data

1. Perhitungan Normalisasi Gain

Setelah melakukan penelitian, data yang diperoleh dari skor pretes dan skor postest kemampuan berpikir kreatif siswa. Adapun data pretes dan postes digunakan untuk melihat peningkatan N-Gain kemampuan berpikir kreatif siswa. Menghitung Normalisasi Gain antara nilai rata-rata pretest dan nilai ratarata postest secara keseluruhan, dengan menggunakan rumus (David E. Meltzer, 2002).

Normalisasi Gain $=\frac{\text { Nilai Postes }- \text { Nilai Pretes }}{\text { Nilai Maksimum }- \text { Nilai Pretes }} \times 100 \%$

Tabel 1. Kriteria Peningkatan Gain

\begin{tabular}{cc}
\hline Gain Ternormalisasi $(\mathrm{G})$ & Kategori Peningkatan \\
\hline $\mathrm{G}<0,5$ & Peningkatan rendah \\
$0,5 \leq \mathrm{G} \leq 0,7$ & Peningkatan sedang \\
$\mathrm{G}>0,7$ & Peningkatan tinggi \\
\hline
\end{tabular}

2. Analisis Data

Penelitian ini menggunakan dua jenis analisis, yaitu:

(1) Analisis deskriptif khususnya bagi variabel yang bersifat kualitatif. Digunakan untuk melihat dan menjelaskan tiap variabel 
(2) Analisis kuantitatif berupa pengujian hipotesis dengan menggunakan uji statistic yang menitik beratkan pada pengungkapan perilaku variabel tersebut. Dengan menggunakan kombinasi metode analisis tersebut dapat diperoleh generalisasi yang komperhensif.

3. Uji Prasyarat Statistik

Uji Normalitas digunakan untuk mengetahui kondisi data apakah berdistribusi normal atau tidak. Kondisi data berdistribusi normal menjadi syarat untuk menguji hipotesis menggunakan statistik parametris. Pengujian normalitas data menggunakan uji Kolmogorov Smirnov dengan menggunakan bantuan software komputer SPSS versi 24. Kriteria pengujiannya adalah jika nilai sign. (signifikansi) atau nilai probabilitas $<0,05$ maka distribusi data tidak normal. Sedangkan jika nilai sign. (signifikansi) atau nilai probabilitas $>0,05$ maka distribusi data normal

4. Pengujian Hipotesis

Uji T (Pretes - Postes)

Rumus uji-t yang digunakan dalam penelitian ini separated varians karena jumlah sampel penelitiannya sama, rumus tersebut dalam persamaan (3) :

$$
\mathrm{t}=\frac{\bar{x}_{1}-\bar{x}_{2}}{\sqrt{\left(\frac{s_{1}^{2}}{n_{1}}\right)-\left(\frac{s_{2}^{2}}{n_{2}}\right)}}
$$

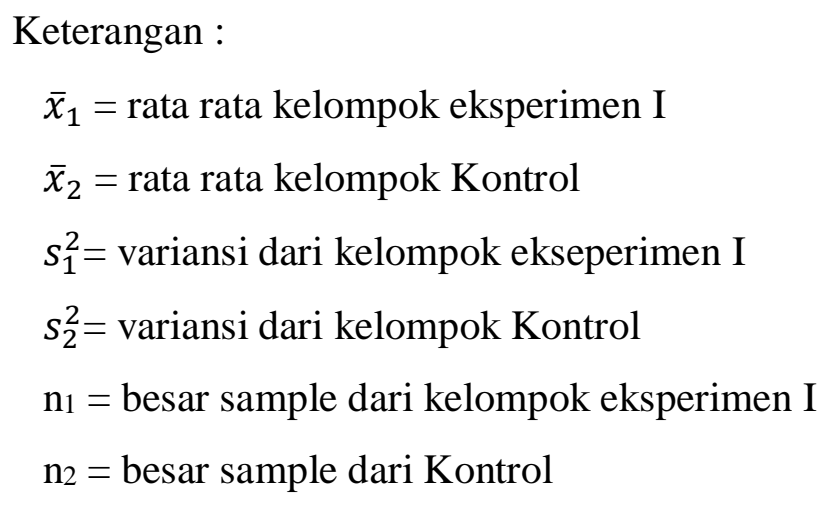

Setelah dilakukan t-test, maka untuk mengetahui perbedaan itu signifikan atau tidak maka harga thitung tersebut perlu dibandingkan dengan ttabel dengan $\mathrm{dk}=\mathrm{n} 1+\mathrm{n} 2-2$ dan taraf kepercayaan 95\%. Kriteria pengujian untuk daerah penerimaan dan penolakan hipotesis adalah sebagai berikut: 
- Tolak $\mathrm{H}_{0}$, dan terima $\mathrm{H}_{1}$ jika thitung > ttabel maka $\mathrm{H} 0$ ditolak artinya signifikan

- Terima $\mathrm{H}_{0}$, dan tolak $\mathrm{H}_{1}$ jika thitung < ttabel maka $\mathrm{H} 0$ diterima artinya tidak signifikan

\section{T-Test Uji Beda Dua Mean Independent}

Jenis data yang digunakan berskala interval atau rasio. Terdapat dua rumus uji t untuk sampel independent yaitu independent sample t-test ( Uji-t) dengan langkah-langkah secara manual. Berikut rumus uji independent sample t-test ( Uji-t) :

$$
t_{\text {hitung }}=\frac{X 1-X 2}{\sqrt{\frac{(\mathrm{n} 1-1) s_{1}+(\mathrm{n} 2-1) s_{12}}{n 1+n 2-2}}\left(\frac{1}{\mathrm{n} 1}+\frac{1}{\mathrm{n} 2}\right)}
$$

Berdasarkan rumus tersebut dapat diketahui, ada 3 jenis nilai yang harus terlebih dahulu kita persiapkan, yaitu :

$\mathrm{X}$ : adalah rata-rata skor / nilai kelompok i.

ni : adalah jumlah responden kelompok i

si2 : adalah variance skor kelompok i.

Setelah dilakukan t-test, maka untuk mengetahui adanya perbedaan atau tidak adanya perbedaan maka harga thitung tersebut perlu dibandingkan dengan ttabel. Kriteria pengujian untuk daerah penerimaan dan penolakan hipotesis adalah sebagai berikut:

- Tolak $\mathrm{H}_{0}$, dan terima $\mathrm{H}_{1}$ jika thitung > ttabel maka $\mathrm{H} 0$ ditolak artinya ada perbedaan

- Terima $\mathrm{H}_{0}$, dan tolak $\mathrm{H}_{1}$ jika thitung < ttabel maka $\mathrm{H} 0$ diterima artinya tidak ada perbedaan

\section{HASIL DAN PEMBAHASAN}

Hasil perhitungan menunjukkan kemampuan berfikir kritis peserta didik kelas eksperimen II dengan nilai Sig (2-Tailed) lebih kecil dari nilai $\alpha=0,05$ sehingga dapat disimpulkan bahwa hipotesis dapat diterima. Rata-rata kemampuan berfikir kritis peserta didik setelah pembelajaran menggunakan 
metode Think-Pair Share lebih tinggi dibandingkan sebelum pembelajaran menggunakan metode Think-Pair Share. Hal ini dapat dilihat dari tabel 2.

Tabel 2. Hasil Uji Hipotesis I

\begin{tabular}{|c|c|c|c|c|c|c|c|c|c|}
\hline & & \multicolumn{5}{|c|}{ Paired Differences } & \multirow[b]{3}{*}{$\mathrm{t}$} & \multirow[b]{3}{*}{ df } & \multirow{3}{*}{$\begin{array}{l}\text { Sig. (2- } \\
\text { tailed) }\end{array}$} \\
\hline & & \multirow{2}{*}{ Mean } & \multirow{2}{*}{$\begin{array}{l}\text { Std. } \\
\text { Deviat } \\
\text { ion } \\
\end{array}$} & \multirow{2}{*}{$\begin{array}{l}\text { Std. } \\
\text { Error } \\
\text { Mean } \\
\end{array}$} & \multicolumn{2}{|c|}{$\begin{array}{c}\text { 95\% Confidence } \\
\text { Interval of the } \\
\text { Difference } \\
\end{array}$} & & & \\
\hline & & & & & Lower & Upper & & & \\
\hline $\begin{array}{c}\text { Pair } \\
1\end{array}$ & $\begin{array}{l}\text { PreTest - } \\
\text { PostTest }\end{array}$ & $\begin{array}{c}24,08 \\
3\end{array}$ & 3,516 & 0,586 & $\begin{array}{c}- \\
25,273\end{array}$ & $-22,894$ & $-41,094$ & 35 & 0,000 \\
\hline
\end{tabular}

Sumber: Hasil Pengolahan Data SPSS 24

Selanjutnya Hasil perhitungan menunjukkan kemampuan berfikir kritis peserta didik kelas eksperimen II dengan nilai Sig (2-Tailed) lebih kecil dari nilai $\alpha=0,05$ sehingga dapat disimpulkan bahwa hipotesis dapat diterima. Ratarata kemampuan berfikir kritis peserta didik setelah pembelajaran menggunakan metode Two Stay - Two Stray lebih tinggi dibandingkan sebelum pembelajaran menggunakan metode Two Stay - Two Stray. Hal ini dapat dilihat dari tabel 3 :

Tabel 3. Hasil Uji Hipotesis II

\begin{tabular}{|c|c|c|c|c|c|c|c|c|c|}
\hline & & \multicolumn{5}{|c|}{ Paired Differences } & \multirow[b]{3}{*}{$\mathrm{t}$} & \multirow[b]{3}{*}{$\mathrm{df}$} & \multirow{3}{*}{$\begin{array}{l}\text { Sig. } \\
(2- \\
\text { tailed })\end{array}$} \\
\hline & & \multirow{2}{*}{ Mean } & \multirow{2}{*}{$\begin{array}{c}\text { Std. } \\
\text { Deviatio } \\
\mathrm{n}\end{array}$} & \multirow{2}{*}{$\begin{array}{l}\text { Std. } \\
\text { Error } \\
\text { Mean }\end{array}$} & \multicolumn{2}{|c|}{$\begin{array}{c}95 \% \text { Confidence } \\
\text { Interval of the } \\
\text { Difference }\end{array}$} & & & \\
\hline & & & & & Lower & Upper & & & \\
\hline Pair 1 & $\begin{array}{c}\text { Pre Test } \\
- \text { Post } \\
\text { Test }\end{array}$ & $-39,667$ & 6,920 & 1,153 & $-42,008$ & $-37,325$ & $-34,393$ & 35 & 0,000 \\
\hline
\end{tabular}

Sumber: Hasil Pengolahan Data SPSS 24

Hasil perhitungan menunjukan bahwa nilai Sig. sebesar $0,000(0,000<0,05)$ berarti terdapat perbedaan peningkatan kemamuan berfikir kritis peserta didik 
antara kelas eksperimen II dan kelas eksperimen II. Pada Levene's Test terlihat bahwa $\mathrm{F}=1,576(\mathrm{p}=0,127)$ karena $\mathrm{p}$ diatas 0,05 , menunjukkan bahwa tidak ada perbedaan varian pada nilai post testberarti data bersifat equal atau homogen. Terlihat pada t-test for Equality of Mean bahwa nilai t Hitung sebesar 10, 590 signifikasni $>0.05$ artinya $\mathrm{t}$ hitung lebih besar dari t tabel 1,9944 (dengan $\mathrm{df}=$ 70).

Dari hasil ini dapat dikatakan bahwa ada perbedaan kemampuan berfikir kritis peserta didik pada kelas yang menggunakan metode Think-Pair Share dengan kelas yang menggunakan metode Two Stay - Two Stray, hasil berdasarkan pada tabel 4 . beikut ini :

Tabel 4. Hasil Peningkatan Kemampuan Berfikir Kritis Peserta didik pada Kelas eksperimen I dan Kelas eksperimen II

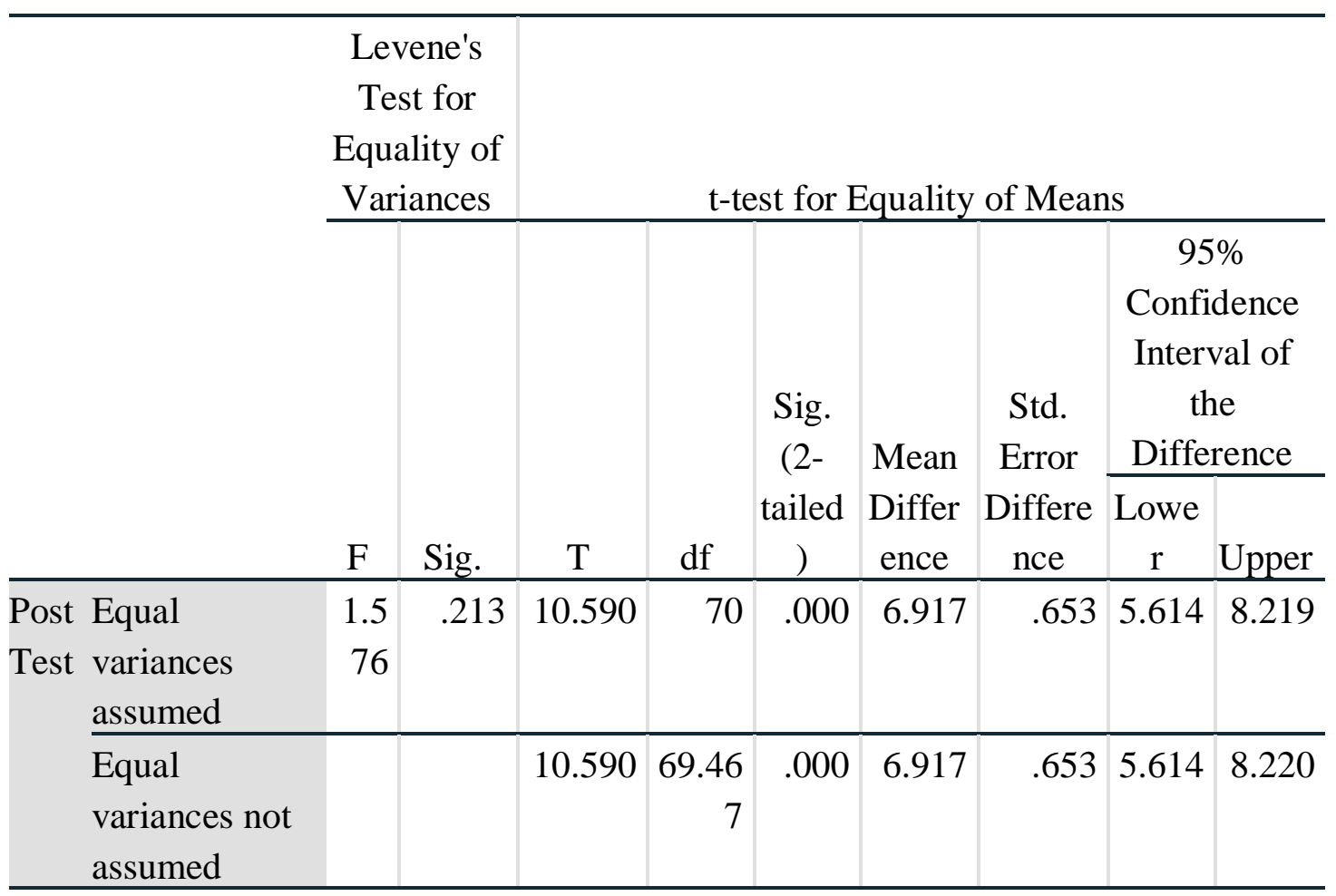

Sumber: Hasil Pengolahan Data SPSS 24

Berdasarkan hasil penelitian ini ditemukan bahwa perbedaan peningkatan kemampuan berfikir kritis peserta didik antara kelas ekperimen yang diberikan 
perlakuan model pembelajaran Think-Pair Share dan kelas eksperimen II yang diberikan perlakuan model pembelajaran Two Stay- Two Stray yang mana peningkatan kemampuan berfikir kritis peserta didik yang menggunakan model pembelajaran Think-Pair Share menunjukkan peningkatan yang lebih tinggi dibandingkan dengan peserta didik yang diberikan perlakuan model pembelajaran Two Stay- Two Stray. Model pembelajaran Think-Pair Share mempunyai pengaruh yang sedikit lebih tinggi terhadap peningkatan kemampuan berfikir kritis peserta didik dibandingkan dengan model pembelajaran Two Stay- Two Stray.

\section{SIMPULAN}

Berdasarkan hasil analisis data dan pembahasan secara umum dapat ditark kesimpulan bahwa penerapan model pembelajaran Think-Pair Share dan model pembelajaran Two Stay - Two Stray dapat meningkatkan kemapuan berfikir kritis peserta didik

Model pembelajaran Think-Pair Share lebih disarankan digunakan dalam pembelajaran sebab model pembelajaran Think-Pair Share mempunyai pengaruh yang sedikit lebih tinggi dibandingkan dengan model pembelajaran Two Stay - Two Stray. Dengan penerapan model pembelajaran ini peserta didik diharapkan mampu memecahkan masalah dunia nyata baik dalam proses pembelajaran maupun stelah berada dalam lingkungan masyarakat ataupun lingkungan kerja.

\section{REFERENSI}

Ahmad, N. I. K. (2008). Collaborative Teaching Think-Pair-Share Technique Nik Azlina Binti Nik Mahmood Dissertation Submitted In Partial Fulfilment Of The Requirements For The Degree Of Master Of Software Engineering Faculty Of Computer Science And Information Technology Kuala L, (September).

Ali, M., \& Noordin, S. (2010). Hubugan Antara Kemairan Berfikir Kritis 
dengan Pencapaian Akademik dalam Kalangan Pelajar Fakulti Pendidikan Universiti Teknologi Malaysia, 45-55.

Anderson, T., Howe, C., R., S., Halliday, J., \& Low, J. (2001). Peer interaction and the learning of critical thinking skills in further education students. Instructional Science, 29, 1-32.

Andhika, N. D. (2013). Experimentation of Matematics Learnng by Using Cooperative Model Type Two Stay Two Stray (TSTS) on Te Subject of a Circle Viewed from Student's Critical Thinking Abilit in Grade of SMP N 1 Surakarta.

Astuti, L. D. (2016). Pengembangan Perangkat Pembelajaran Fisika Aktif Tipe Information Search berbasis Kearifan Lokal DIY untuk Meningkatkan Kemampuan Berfikir Kritis dan nilai karakter Siswa.

Beyer, B. K. (2008). How to Teach Thinking Skills in Social Studies and History. The Social Studies, 99(5), 196-201. https://doi.org/10.3200/TSSS.99.5.196-201

Bolkan, S., \& Goodboy, A. K. (2009). Transformational Leadership in the Classroom: Fostering Student Learning, Student Participation, and Teacher Credibility. Journal of Instructional Psychology. Dec2009, 36(4), 296-306. https://doi.org/Article

Brookfield, S. D. (2006). The Skillful Teacher On Technique, Trust, and Responsiveness in the Classroom.

Duron, R., Limbach, B., \& Waugh, W. (2006). Critical Thinking Framework For Any Discipline. International Journal of Teaching and Learning in Higher Education, 17(2), 160-166. https://doi.org/10.1016/j.nepr.2006.09.004

Efendi, N. (2013). Pengaruh Pembelajaran Reciprocal Teaching Dipadukan Think Pair Share Terhadap Peningkatan Kemampuan Metakognitif Belajar Biologi Siswa SMA Berkemampuan Akademik Berbeda di Kabupaten Sidoarjo. Jurnal Santiaji Pendidikan (JSP), 3(2), 85-109.

Ennis, R. (1991). Critical thinking. Teaching Philosophy, 14(1), 5-24. https://doi.org/10.1016/B978-0-12-375038-9.00057-1

Ennis, R. H. (1993). Critical thinking assessment. Theory Into Practice, 32(3), 179-186. https://doi.org/10.1080/00405849309543594

Enung Sumaryati, U. S. (2013). Pendekatan Induktif-Deduktif Disertai Strategi Think-Pair-Square-Share Untuk Meningkatkan Kemampuan Pemahaman Dan Berpikir Kritis Serta Disposisi Matematis Siswa SMA, 2(1), 26-42. 
Felder, R. M., Brent, R., \& Carolina, N. (2009). Active Learning : An Introduction, 2(August).

Fitzgerald, D. (2013). Employing think-pair-share in associate degree nursing curriculum. Teaching and Learning in Nursing, 8(3), 88-90. https://doi.org/10.1016/j.teln.2013.01.006

Frijters, S., ten Dam, G., \& Rijlaarsdam, G. (2008). Effects of dialogic learning on value-loaded critical thinking. Learning and Instruction, 18(1), 66-82. https://doi.org/10.1016/j.learninstruc.2006.11.001

Gokhale, A. A. (1995). Collaborative Learning Enhances Critical Thinking. Journal of Technology Education, 7(1). https://doi.org/10.21061/jte.v7i1.a.2

Halpern, D. E. (1997). Teaching Critical Thinking for Transfer Across Domains Dispositions, Skills, Structure Training, and Metacognitive Monitoring.

Halpern, D. F. (1998). Teaching critical thinking for transfer across domains. American Psychologist, 53(4), 449-455. https://doi.org/10.1037//0003066X.53.4.449

Hamiddin. (2012). Improving Students' Comprehension of Poems Using Two Stay-Two Stray Strategy. Jurnal Vidya Karya, 27(1), 1-8.

Harahap, F. A. (2010). Improving Students' Reading Comprehension Through Two Stay - Two Stray Learning Model.

Harpaz, Y. (2005). Teaching and learning in a community of thinking. Journal of Curriculum \& Supervision, 20(2), 136-157. https://doi.org/10.1007/978-94-007-6940-3

Hasunatun Munawaroh, Mursidah Rahmah, M. Pd, Atti Herawati, M. P. (2013). 1 THE EFFECT OF TWO STAY TWO STRAY ON STUDENTS' READING ABILITY, (May 2013), 1-9.

Hidayat, W. (2012). Meningkatkan Kemampuan Berpikir Kritis Dan Kreatif Matematik Siswa Sma Melalui Pembelajaran Kooperatif Think-TalkWrite (TTW), 1-10.

Jackson, S. L. (2009). A Critical Thinking Approach.

Jannah, N. (2013). The Effectiveness Of Think-Pair-Share Technique In Teaching Reading, 1(12), 91-96.

Jones, A. (2005). Culture and context: Critical thinking and student learning in introductory macroeconomics. Studies in Higher Education, 30(3), 339354. https://doi.org/10.1080/03075070500095788 
Kaddoura, M. (2012). Think Pair Share: A teaching Learning Strategy to Enhance Students' Critica...: EBSCOhost.

Kong, L.-N., Qin, B., Zhou, Y., Mou, S., \& Gao, H.-M. (2014). The effectiveness of problem-based learning on development of nursing students' critical thinking: A systematic review and meta-analysis. International Journal of Nursing Studies, 51(3), 458-469. https://doi.org/10.1016/j.ijnurstu.2013.06.009

Kong, S. C. (2014). Developing information literacy and critical thinking skills through domain knowledge learning in digital classrooms: An experience of practicing flipped classroom strategy. Computers and Education, 78, 160-173. https://doi.org/10.1016/j.compedu.2014.05.009

Kothiyal, A., Majumdar, R., Murthy, S., \& Iyer, S. (2013). Effect of Think-PairShare in a Large CS1 Class: 83\% Sustained Engagement. Proceedings of the Ninth Annual International ACM Conference on International Computing Education Research, 137-144. https://doi.org/10.1145/2493394.2493408

Kwok, A. P., \& Lau, A. (2015). An Exploratory Study on Using the Think-PairShare Cooperative Learning Strategy, 2, 22-28.

Lai, E. R. (2011). Metacognition: A Literature Review Research Report. Research Reports, (April), 41. https://doi.org/10.2307/3069464

Lewaherilla, A. (2011). Improving Students' Reading Competence Through Two Stay Two Stray Technique.

MacKnight, B. (2000). Teaching Critical Thinking through Online Discussions. Educause Quarterly, 23(4), 38-41. Retrieved from https://net.educause.edu/ir/library/pdf/EQM0048.pdf

Mason, M. (2009). Critical Thinking and Learning Process for Student in Two major Fields. Educational Philosophy and Theory. https://doi.org/10.1111/j.1469-5812.2007.00343.x

McKendree, J., Small, C., Stenning, K., \& Conlon, T. (2002). The role of representation in teaching and learning critical thinking. Educational Review, 54(1), 57-67. https://doi.org/10.1080/00131910120110884

Paul, R. W. (1989). Critical Thinking in North America: A New Theory of Knowledge, Learning, and Literacy, 197-235.

Paulsen, M. B. (2013). Higher Education: Handbook of Theory and Research.

Permadi Marhaeni, I. M., Putra, A., \& Nyoman Adi Jaya, I. (2013). the Effect of Think Pair Share Teaching Strategy To Students' Self-Confidence and 
Speaking Competency of the Second Grade Students of Smpn 6 Singaraja, 1 .

Scanniello, G., \& Erra, U. (2014). Distributed modeling of use case diagrams with a method based on think-pair-square: Results from two controlled experiments. Journal of Visual Languages and Computing, 25(4), 494517. https://doi.org/10.1016/j.jvlc.2014.03.002

Sianipar, D. M. (2013). Improving Students ' Achievement In Speakin G Through Two Stay Two Stray Strategy.

Surjosuseno, T. T. (2011). the Effects of "O Ne Stays the Rest Stray" and " Lockstep "Techniques on the Enhancement of Students ' Reading. Indonesian Journal of Applied Linguistics, I(1), 123-139. https://doi.org/10.17509/ijal.v1i1.104

TANJUNG, M. (2015). The Effect Of Tsts ( Two Stay Two Stray ) Technique To The Students ' Reading Ability At The Tenth Grade In Smk Negeri 1 Kediri Academic Year 2014 / 2015.

Tiasto, R. H. (2015). The effect of learning models missouri mathematics project with two stay two stray methods for mathematical problem solving ability of students in 7 .

Trent, K. S. (2013). The Effects Of The Peer Instruction Technique Think-PairShare On Students' Performance In Chemistry, (August).

Willingham, D. T. (2010). “21st-Century” Skills, 17-20. 